\title{
Population genetic structure of Australian magpies: evidence for regional differences in juvenile dispersal behaviour
}

\author{
ANDREW M. BAKER*†, PETER B. MATHER $\uparrow \&$ JANE M. HUGHES $\ddagger$ \\ $\dagger$ School of Natural Resource Sciences, Queensland University of Technology, Gardens Point Campus, \\ GPO Box 2434, Brisbane, Queensland, 4001, Australia and $₫$ Australian School of Environmental Studies, \\ Griffith University, Nathan, Queensland, 4111, Australia
}

\begin{abstract}
Territorial group size in Australian magpies (Gymnorhina tibicen) ranges from monogamous pairs to groups of more than 20 individuals. It has been hypothesized that large territorial groups result from the retention of juveniles after a breeding effort. If this is true, local populations consisting of large groups are likely to exhibit the most genetic structure, because over time similar genotypes will tend to be confined to limited areas if juveniles are predominantly philopatric. The objective of the present study was to test this hypothesis using allozyme and mitochondrial DNA data to provide indirect estimates of regional gene flow (derived from hierarchical population subdivision analyses). These data were used in combination with estimates of group size to infer patterns of dispersal among magpie populations across mainland Australia. Territorial groups were significantly larger in the south-west compared to three eastern regions. Although inferred levels of gene flow were substantial for all four regions, a striking pattern emerged from both sets of genetic data: more differentiation was evident among populations in the south-western region than in any eastern region. We conclude that levels of juvenile dispersal influence group size in G. tibicen, because in the south-western region where groups were largest, populations were most genetically differentiated. Our results suggest that contrasting population genetic structures may develop within a single species as a result of differences in social system.
\end{abstract}

Keywords: allozymes, Australian magpie, bird, dispersal, gene flow, mitochondrial DNA.

\section{Introduction}

A characteristic feature of most vertebrates is the permanent movement made by offspring from the site of their birth to their first breeding locality (natal dispersal) and, less conspicuously, subsequent movement from one breeding site to another either within or between breeding seasons (breeding dispersal) (Greenwood et al., 1979).

Ecologists have debated for many years why animals leave the relative safety of where they were born in search of a new home they may not even find (Dobson et al., 1998). Costs of such behaviour may include a greater risk of mortality and a lack of knowledge of the new site that may make it more difficult to find food, mates and nesting sites (Fleischer et al., 1984). There are also potential difficulties associated with entering established sites and sequestering a new territory (Myers,

\footnotetext{
*Correspondence. E-mail: kingoftrees@hotmail.com
}

1974). On the other hand, several benefits may accrue to successful dispersers thus favouring the evolutionary maintenance of dispersal behaviour, e.g. better access to environmental resources such as food and social resources such as mates (Dobson et al., 1998), avoidance of inbreeding depression (Koenig \& Pitelka, 1979) and lower exposure to predators and disease (Stenseth \& Lidicker, 1992). Overall therefore, the consequences of dispersal can range from premature death without reproducing, to discovery and exploitation of a highquality habitat patch with an ideal mate (Gadgil, 1971).

Provided that a disperser reproduces, the most important consequence of dispersal from a genetic perspective is that it results in gene flow. There is no clear relationship between small-scale dispersal (i.e. of individuals within a generation) and genetic variation within a population. However, the effect of large-scale dispersal (i.e. over longer times and larger distances) has been clearly recognized; it will cause diffusive flow of genes, impede local adaptation and reduce stochastic 
variation (Barton, 1992). In essence, if gene flow is extensive there will be a tendency for all segregating alleles to be found in all populations of a species, increasing genetic similarity among populations (Greenwood, 1987). Species for whom dispersal distances are large and/or dispersal is common are likely therefore to exhibit a homogeneous genetic structure (Barton, 1992). Conversely, if gene flow is not extensive the genetic similarity among populations will decrease, because specific alleles will tend to be restricted to limited geographical ranges (Greenwood, 1987); such a population genetic structure may be exhibited by a species whose dispersal distances are small and/or where offspring are predominantly philopatric (Barton, 1992).

Australian magpies (Gymnorhina tibicen) are groupliving passerines which are hypothesized to employ a number of different dispersal strategies; an ideal species for a comparative study of the effect of dispersal on population genetic structure.

In an early study of a Canberra (ACT) magpie population, Carrick (1972) reported that whereas adults were site-tenacious, most juveniles from the previous year dispersed from natal territories when parental birds commenced their annual breeding effort. Dispersing juveniles usually joined nonbreeding flocks where they remained for a limited time before either establishing their own territory or being recruited into an already established territory, generally within a mile of their birthplace.

Recently, however, Hughes \& Mather (1991) estimated territory group size in a number of magpie populations across Australia and provided indirect evidence that juvenile dispersal behaviour varies among localities. They believed that group size was related to geographical locality; monogamous pairs were common in northeastern populations but mean group size increased down the east coast of the continent and across the south coast to Western Australia, where territorial groups were composed of as many as 26 individuals (Robinson, 1956). Hughes \& Mather (1991) postulated that larger group sizes in the south-east and south-west of the continent were related to a higher incidence of juvenile philopatry.

Putative differences in magpie group size among localities may result from any or all of the following: (1) differential dispersal (parents may force their offspring out of natal territories only in certain regions); (2) geographical differences in the number of young fledged per group; or (3) geographical differences in the rate of fledgling survival. The last two possibilities are difficult to investigate because they require long-term demographic data to account for potential temporal changes in resources. The question of differential dispersal, however, can be addressed relatively easily by applying population genetic models to genetic data collected for magpie populations.

The present study seeks to relate the degree of genetic differentiation among magpie populations within four regions to social organization (the size of territorial groups). If large groups of magpies are more tolerant of the presence of subadults and inferior adults then dispersal will be reduced, resulting over time in greater genetic differentiation (and lower gene flow) across relatively small spatial scales compared to areas where offspring are commonly forced from the natal territory after each breeding effort.

In the past, researchers have attempted to quantify gene flow using direct estimation methods (e.g. markrecapture, observation of marked animals). Such techniques indicate gene flow at a particular time and are thus insensitive to rare events, such as long-distance dispersal and major changes in population structure, that may not occur during the period of observation. In contrast, indirect methods of estimation, which are based on the analysis of gene frequencies, have the advantage that they necessarily depend upon levels of gene flow averaged over longer time-frames (Slatkin, 1987).

In this study, we apply the latter method to determine genetic structure using two markers, allozymes and mtDNA. Allozyme electrophoresis has been used widely as an indirect method to estimate gene flow among bird populations (e.g. Barrowclough et al., 1981; Cooke et al., 1988; Friesen et al., 1996); mtDNA is particularly valuable for studying gene flow because its evolution may be as much as 10 times faster than that of nuclear DNA and it yields an effective population size onequarter that of nuclear DNA. This means that a population can be effectively subdivided for mitochondrial genes at migration rates for which nuclear genes are still in panmixia (Birky et al., 1983).

Specifically, in this study genetic data will be used in combination with group size data to test the following hypothesis: genetic differentiation among $G$. tibicen subpopulations is greatest in geographical regions where group sizes are largest.

\section{Materials and methods}

\section{Sampling methodology}

A two-level sampling hierarchy was adopted: four geographical regions were sampled and within each region magpie populations were collected from four approximately equidistant sites, with balanced sampling effort at each site (Fig. 1).

This is the first study to investigate the relationship between dispersal and group size in this species, and we 


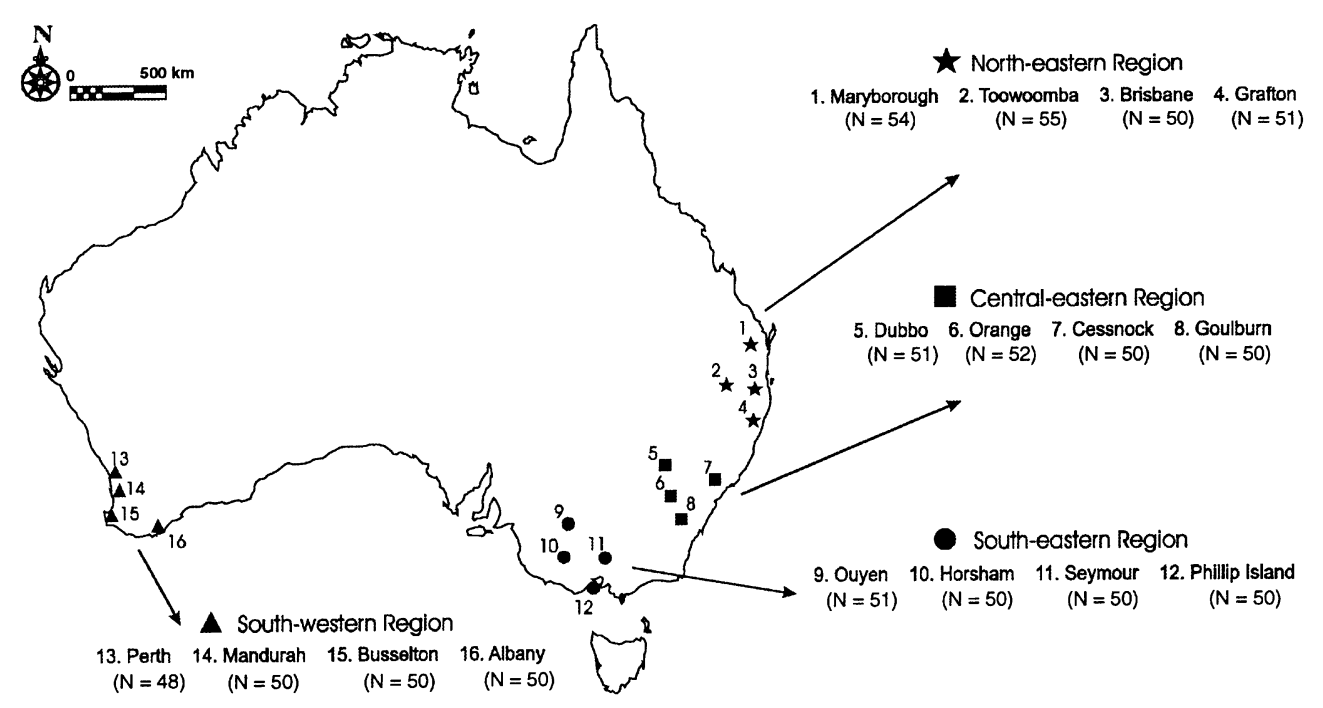

Fig. 1 Location of study sites for populations of Australian magpies (Gymnorhina tibicen).

intentionally chose a regional rather than a microgeographical spatial sampling scale, because we had evidence of broad-scale differences in group size (Hughes \& Mather (1991) measured group size in 13 magpie populations ranging across the entire Australian continent), but we had no knowledge of how group size varied over small geographical distances. Based on the differences observed by Hughes and Mather, we targeted geographical regions supporting populations for which group size was predicted to differ. Our aim was: (1) to determine to what extent group size varied among the sampled regions and to compare these results to those obtained by Hughes and Mather; (2) to determine if there were regional differences in gene flow; and (3) to determine if patterns of regional gene flow and group size were consistent.

Sampling was conducted between March 1994 and November 1996. A minimum of $80 \mathrm{~km}$ separated sampled populations within each region, to ensure that individuals would be unlikely to disperse directly between them. No more than two individuals were sampled per territory (only adults were taken where possible to avoid biasing population allele frequencies by over-representation of individual lineages). Wild magpies were entrapped using a decoy magpie housed in a small birdcage within a wire enclosure with a tapered cone entrance. A small blood sample (approx. $200 \mu \mathrm{L}$ ) was taken from each captured individual. Blood samples were stored at $-80^{\circ} \mathrm{C}$.

\section{Estimation of group size}

Group size was estimated for each sampled territory by counting the number of wild magpies that approached within $30 \mathrm{~m}$ of a live decoy magpie (positioned inside the territory boundary). This method was adopted because: (1) wild territorial magpies will always attack a live decoy magpie; and (2) all magpies past first moult participate in territory defence (Carrick, 1972). If after a period of 20 min no new group members were observed, the count was terminated. It was assumed that group size did not vary temporally, because in a previous study Hughes \& Mather (1991) found no significant change in mean group size between years in Brisbane (north-eastern region) and Perth (south-west) magpie populations.

\section{Laboratory methodology}

(a) Allozymes Thirty-six enzyme loci were initially screened using cellulose acetate gel electrophoresis (Titan III Zip Zone Cellulose Acetate Plates, Helena Laboratories). Six polymorphic loci were identified in blood and could be scored with confidence (a single locus coded for each enzyme). These loci were $\beta$-esterase ( $\beta$ Est; EC 3.1.1.1), glucose-phosphate isomerase $(G p i$; EC 5.1.3.9), Isocitrate dehydrogenase (Idh; EC 1.1.1.42), mannose-phosphate isomerase (Mpi; EC 5.3.1.8), phosphoglucomutase (Pgm; EC 2.7.5.1) and 6-phosphogluconate dehydrogenase (6Pgd; EC 1.1.1.44). Electrophoresis and staining procedures were performed as outlined in Richardson et al. (1986).

(b) MtDNA Total genomic DNA was extracted using $50 \mu \mathrm{L}$ of whole blood from each sample. After $10 \mathrm{~min}$ centrifugation, the pellet was resuspended in $950 \mu \mathrm{L}$ extraction buffer (200 mM Tris pH 8.0; $250 \mathrm{~mm} \mathrm{NaCl}$; 25 mм EDTA; $0.5 \%$ SDS); $112 \mu \mathrm{L}$ of $10 \%$ nonidet P-40

(C) The Genetical Society of Great Britain, Heredity, 85, 167-176. 
was added and samples were left undisturbed at room temperature for $30 \mathrm{~min}$. Following this, samples were immersed in a $70^{\circ} \mathrm{C}$ water bath for $5 \mathrm{~min}$ and then centrifuged for $15 \mathrm{~min}$. Proteins and lipids were removed by phenol extraction, and then a series of phenol:chloroform:isoamyl-alcohol (25:24:1) and chloroform:isoamyl-alcohol (24:1) extractions. DNA was precipitated with $100 \mu \mathrm{L}$ of $3 \mathrm{M}$ sodium acetate and $400 \mu \mathrm{L}$ isopropanol, washed with $70 \%$ ethanol, resuspended in $40 \mu \mathrm{L}$ TE buffer and stored at $-80^{\circ} \mathrm{C}$.

Two specific primers were designed to generate a 590-bp control-region fragment for use in Temperature Gradient Gel Electrophoresis (TGGE). Primer 1 (sequence 5'-GGA ACC AGA GGC GCA AAA GAG C- $3^{\prime}$ ) was located in the D-Loop Domain II and primer 2 (sequence 5'-CAA GAT CTG TGG CTT GAA AAG CC- $3^{\prime}$ ) was located in the tRNA ${ }^{\text {Glu }}$ adjacent to the D-Loop. PCR reactions were performed in a $50-\mu \mathrm{L}$ total volume. Reactions contained: $16.75 \mu \mathrm{L} \mathrm{ddH}_{2} \mathrm{O}, 5 \mu \mathrm{L}$ Perkin Elmer 10× Buffer II, $4 \mu$ L Perkin Elmer $25 \mathrm{~mm}$ $\mathrm{MgCl}_{2}, 16 \mu \mathrm{L}$ Promega $10 \mathrm{~mm}$ deoxynucleoside triphosphates (2.5 mM each), $3 \mu \mathrm{L} 25 \mu \mathrm{M}$ Primer $1,3 \mu \mathrm{L} 25 \mu \mathrm{M}$ Primer 2, 1.25 units Perkin Elmer Amplitaq ${ }^{\circledR}$ DNA Polymerase, $200 \mathrm{ng}$ DNA template and $40 \mu \mathrm{L}$ light mineral oil. A negative control solution (without DNA template) was included with each set of reactions. Temperature cycling was conducted in a Hybaid Omnigene Thermal Cycler at: (1) $95^{\circ} \mathrm{C}$ for $5 \mathrm{~min}$; (2) $94^{\circ} \mathrm{C}$ for $1 \mathrm{~min}$; (3) $55^{\circ} \mathrm{C}$ for $1 \mathrm{~min}$; (4) $72^{\circ} \mathrm{C}$ for $1 \mathrm{~min}$, with steps 2-4 repeated 40 times; and $(5) 72^{\circ} \mathrm{C}$ for $10 \mathrm{~min}$. PCR products were stored at $-80^{\circ} \mathrm{C}$.

The DIAGEN horizontal TGGE system (DIAGEN $\mathrm{GmbH}$ ) was used to screen amplified PCR products for variation. A single magpie sample was electrophoresed over a perpendicular gradient of $20-60^{\circ} \mathrm{C}$ to determine the melting temperature of the 590-bp control-region fragment $\left(42^{\circ} \mathrm{C}\right)$, the migration rate $(1.73 \mathrm{~cm} / \mathrm{h})$ and the optimal electrophoretic running time for subsequent parallel TGGE ( $3 \mathrm{~h} 55 \mathrm{~min}$ ). Heteroduplex analysis (TGGE-HA) and subsequent parallel TGGE analysis were performed according to the specifications outlined in the TGGE handbook (1993). Heteroduplex DNA variants were each assigned a distinguishing haplotype.

PCR products from individuals representing each unique haplotype were sequenced in an Applied Biosystems 373A automated DNA sequencer. Resulting sequences were aligned using the CLUSTALW program in the Australian National Genomic Information Service (ANGIS) computer package. Replicate sequencing of each haplotype was performed to confirm that individuals scored by gel as the same haplotype possessed identical DNA sequence. Each sample was sequenced in both directions with overlapping sections to ensure DNA-strand homology.

\section{Analyses}

Group size data were analysed using an analysis of variance (ANOVA) approach (Sokal \& Rohlf, 1995).

Population subdivision estimates were derived from allozyme data by analysis of molecular variance (AMOVA) (Excoffier et al., 1992) using an analogue of $F_{\text {ST }}$ weighted over loci. The absolute number of individuals exchanged between populations per generation was estimated by $N_{\mathrm{e}} m_{\mathrm{e}}$, where: $N_{\mathrm{e}} m_{\mathrm{e}}=\left(1-F_{\mathrm{ST}}\right) /$ $4 F_{\mathrm{ST}}$, assuming neutral alleles under an island model (Wright, 1951).

Population subdivision estimates were derived from mtDNA data using $\Phi$-statistics assessed by AMOvA under permutational procedures (Excoffier et al., 1992). Estimates of $N_{\mathrm{e}} m_{\mathrm{f}}$ (effective female gene flow) were calculated using the relationship: $N_{\mathrm{e}} m_{\mathrm{f}}=1 / 2\left(1 / \Phi_{\mathrm{ST}}-1\right)$ (Hudson et al., 1992).

\section{Results}

\section{Group size}

Mean group size was larger in south-western populations than in eastern populations (Fig. 2). Cochran's $C$-test $\left(C_{(15)}=0.15, \quad P<0.001\right)$ revealed significant heterogeneity among sample variances (natural logarithmic transformation was performed prior to ANOVA). Although significant intraregional variation in group size was observed among south-eastern populations $\left(F_{3,85}=23.49, P<0.001\right)$, nested ANOvA revealed significant differentiation among regions $\left(F_{3,12.35}=11.27\right.$, $P<0.001)$. Post-hoc range tests indicated that the variation was attributable to differences between eastern and south-western regions $(P<0.001$ for all pairwise comparisons); no significant variation in group size was evident among eastern regions $(P>0.05$ for all pairwise comparisons).

\section{Allozymes}

Allele frequencies at the six polymorphic allozyme loci in all populations conformed to Hardy-Weinberg equilibrium. Allelic variation was largest at the Est-1 locus; however, none of the enzyme loci screened was highly polymorphic (Table 1). When individual loci were considered, south-western populations showed more within-region differentiation than eastern populations at five out of six loci (data not shown). Estimates of population subdivision for pooled loci were significantly different from zero in all regions, implying moderate levels of gene flow among populations within each region $\left(N_{\mathrm{e}} m_{\mathrm{e}}\right.$ range $3.83-18.41$; Table 2$)$; the lowest intraregional gene flow occurred in the south-west. 


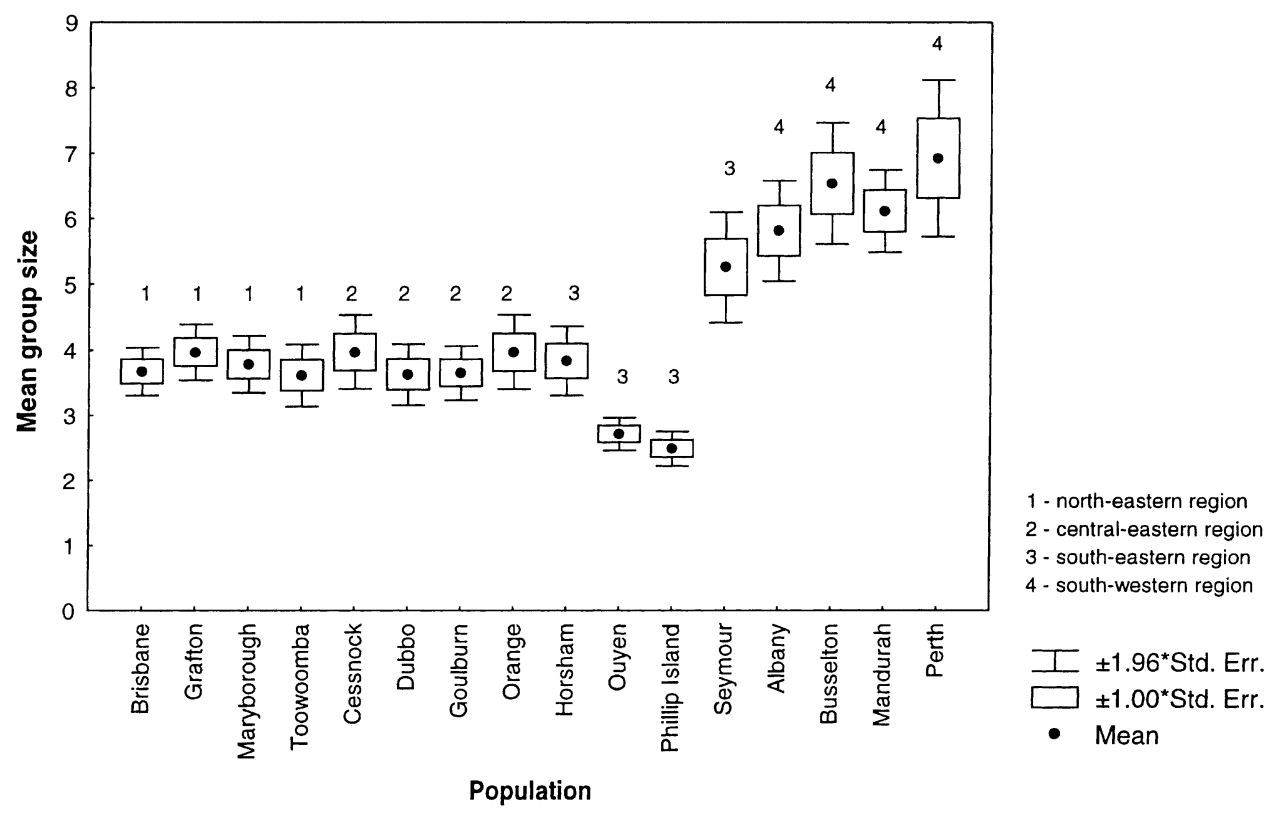

Fig. 2 Graph of mean group size in populations of Australian magpies (Gymnorhina tibicen).

\section{MtDNA}

From a total of 812 individuals assayed, 24 mitochondrial haplotypes were identified (Table 3). No haplotypes were shared between eastern and south-western populations. Haplotypes two and four were shared among all eastern populations; haplotypes 17 and 19 were shared among all south-western populations (Table 3). Among eastern populations $(\mathrm{H} 1-\mathrm{H} 16)$, haplotypes 2, 3, 4 and 6 were found in $85.0 \%(522 / 614)$ of sampled individuals. Among south-western populations (H17-H24), haplotypes 17, 18 and 19 were found in $96.5 \%(191 / 198)$ of sampled individuals. These data reflect the low degree of haplotype endemism within all regions. Nineteen mutational sites were present in the 590-bp control-region fragment. Sequence divergence estimates ranged from $0.17 \%(1 \mathrm{bp})$ to $2.20 \%$ (13 bp) (Table 4). Estimates of population subdivision were significantly different from zero in all regions, implying moderate levels of gene flow among populations within each region $\left(N_{\mathrm{e}} m_{\mathrm{f}}\right.$ range 3.06-10.33; Table 2$)$; lowest intraregional gene flow occurred in the south-west.

\section{Discussion}

\section{Group size}

Results of the present study show that magpies in southwestern Australia live in significantly larger groups than magpies in eastern regions. Mean group size of magpies collected from the south-western region was 6.23 (range $3-11$ ), which falls within the range reported previously for groups of western magpies, e.g. mean 8.00 (range 3-26) in Coolup (Robinson, 1956 in Hughes \& Mather, 1991), mean 8.00 (range 4-15) in Perth (Schmidt, 1987), mean 7.60 (range 4-13) in Perth and mean 5.22 (range 2-8) in Busselton (Hughes \& Mather, 1991).

Carrick (1972) made the general observation that group size is similar throughout the range of G. tibicen in eastern Australia. In contrast, Hughes \& Mather (1991) reported a trend for increasing group size down the east coast of Australia. Regional comparisons of group size in eastern populations in the present study did not support the pattern reported by Hughes and Mather, because only the Seymour (Victoria) population had a significantly larger mean group size than other populations sampled in the east.

A re-examination of the group size data compiled by Hughes \& Mather (1991) revealed no significant differences in mean group size among four eastern Queensland populations (Townsville, Rockhampton, Nambour, Brisbane) and two south-eastern Australia populations (Canberra, Melbourne). Of the eastern populations of magpies they sampled, only the Adelaide population (south-eastern South Australia) exhibited significantly larger mean group size than north-eastern populations. Thus, although there was a general trend of increasing group size down the east coast in the populations Hughes and Mather sampled, this trend was not strongly supported statistically.

Taken together therefore, both the present data and those of Hughes \& Mather (1991) suggest that, in eastern Australia, differences in mean group size are not clearly correlated with geographical locality at a

(C) The Genetical Society of Great Britain, Heredity, 85, 167-176. 
Table 1 Allozyme allele frequencies in populations of Australian magpies (Gymnorhina tibicen)

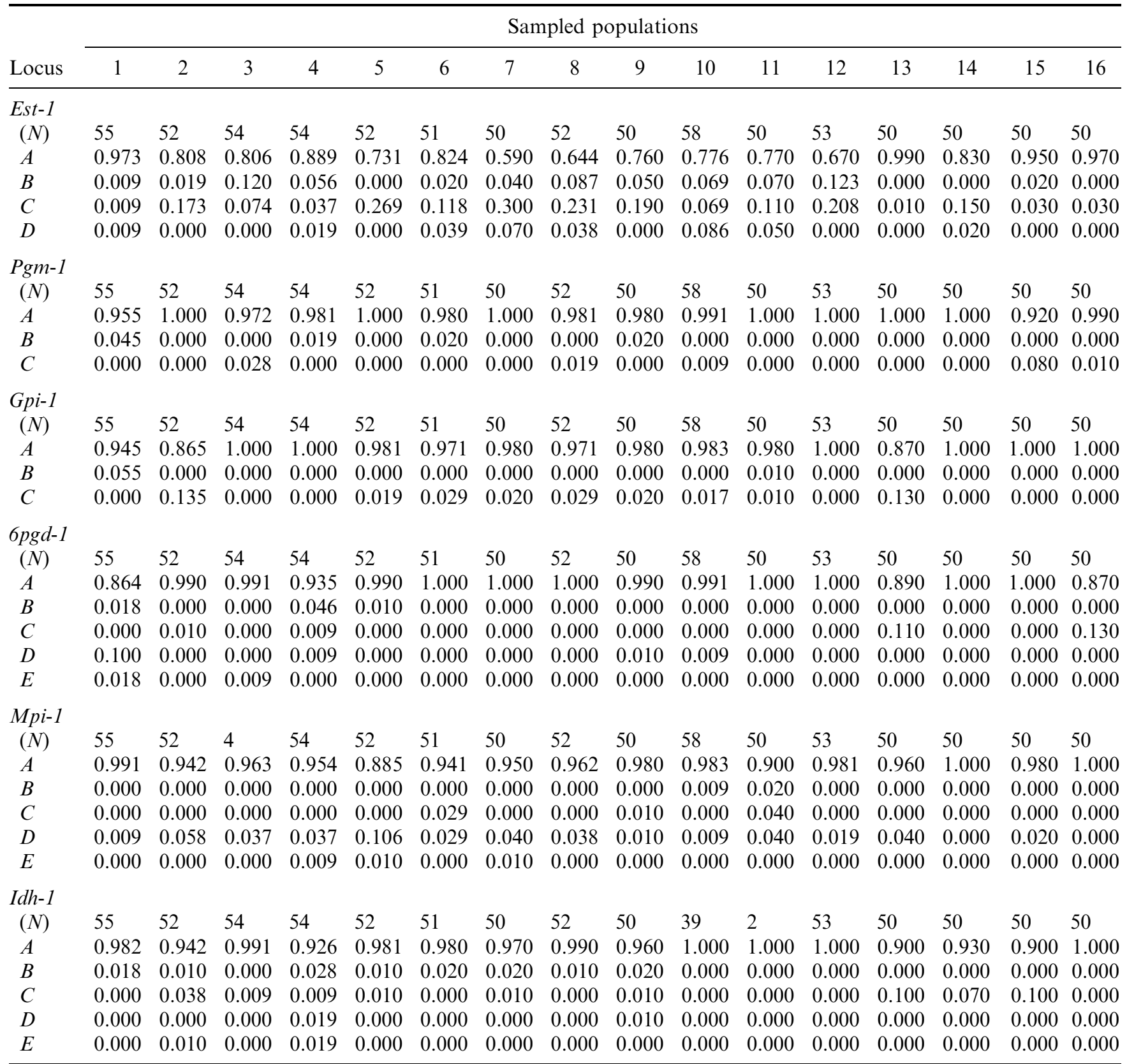

1, Brisbane; 2, Grafton; 3, Maryborough; 4, Toowoomba; 5, Cessnock; 6, Dubbo; 7, Goulburn; 8, Orange; 9, Horsham; 10, Ouyen; 11, Phillip Island; 12, Seymour; 13, Albany; 14, Busselton; 15, Mandurah; 16, Perth.

$(N)$, sample size.

Letters denote alleles.

regional spatial scale. Large territorial groups, characteristic of populations such as Seymour (mean 6.65, Hughes et al., 1996; mean 5.25, the present study) and Adelaide (mean 4.84, Hughes \& Mather, 1991) in eastern Australia, are apparently limited geographically because areas close by these sites (e.g. Melbourne [mean 3.50], Hughes \& Mather, 1991; Phillip Island [mean
2.48], Ouyen [mean 2.70], Horsham [mean 3.83], the present study) exhibited notably smaller mean group size. Thus, if discrete patterns of group size variation exist in eastern Australia, they must occur across smaller spatial scales than could be detected at the geographical scales of investigation employed by either Hughes and Mather or the present study. 


\section{Population genetic structure}

Gene flow has apparently been sufficient to prevent the development of fixed differences (Slatkin, 1987) among magpie populations up to several hundred kilometres apart. This result is particularly significant for estimates of gene flow generated from the mtDNA data, because

Table 2 Population subdivision analysis and inferred levels of gene flow in Australian magpies (Gymnorhina tibicen)

\begin{tabular}{lcrlrr}
\hline & \multicolumn{2}{c}{ Allozymes } & & \multicolumn{2}{c}{ mtDNA } \\
\cline { 2 - 3 } \cline { 6 - 7 } Populations analysed $\dagger$ & $F_{\mathrm{ST}}$ & $N_{\mathrm{e}} m_{\mathrm{e}}$ & & $\Phi_{\mathrm{ST}}$ & $N_{\mathrm{e}} m_{\mathrm{f}}$ \\
\hline NE populations & $0.043^{*}$ & 5.51 & & $0.066^{*}$ & 7.04 \\
CE populations & $0.022^{* *}$ & 11.06 & & $0.046^{*}$ & 10.33 \\
SE populations & $0.013^{* *}$ & 18.41 & & $0.098^{*}$ & 4.59 \\
SW populations & $0.062^{*}$ & 3.83 & & $0.140^{*}$ & 3.06 \\
\hline
\end{tabular}

$\dagger \mathrm{NE}$, north-eastern; CE, central-eastern; SE, south-eastern; and SW, south-western.

$* P<0.001 ; * * P<0.01$. this marker allows greater detection of population genetic differences owing to the fast rate of controlregion evolution (Slatkin \& Maddison, 1989).

Notwithstanding similarities in general levels of intraregional gene flow, a striking pattern emerged: regardless of marker type, gene flow was lowest in the south-western region where groups were largest. For example, estimates of maternal gene flow generated from mtDNA data suggest that the number of females exchanged per generation among south-western populations is less than one-third that for the central-eastern region, less than one-half that for the northeastern region, and only two-thirds that for the southeastern region (differences of similar magnitude were generated from both allozyme data [Table 2] and mtDNA data when sequence divergence among haplotypes was omitted [not shown]). However, even though regional differences in genetic structure between eastern and south-western populations were well-defined, instances of overlapping standard deviations on jackknife fixation indices (not shown) highlight the need for

Table 3 MtDNA haplotype frequencies in populations of Australian magpies (Gymnorhina tibicen)

\begin{tabular}{|c|c|c|c|c|c|c|c|c|c|c|c|c|c|c|c|c|}
\hline & \multicolumn{16}{|c|}{ Sampled populations } \\
\hline & 1 & 2 & 3 & 4 & 5 & 6 & 7 & 8 & 9 & 10 & 11 & 12 & 13 & 14 & 15 & 16 \\
\hline$(N)$ & 50 & 51 & 54 & 55 & 50 & 51 & 50 & 52 & 50 & 51 & 50 & 50 & 50 & 50 & 50 & 48 \\
\hline$H 1$ & 0.040 & 0.274 & & 0.018 & & & & 0.115 & & & & & & & & \\
\hline $\mathrm{H} 2$ & 0.220 & 0.078 & 0.130 & 0.327 & 0.300 & 0.275 & 0.220 & 0.115 & 0.140 & 0.176 & 0.080 & 0.220 & & & & \\
\hline$H 3$ & 0.520 & 0.412 & 0.407 & 0.255 & 0.200 & 0.137 & 0.080 & 0.135 & 0.040 & 0.059 & & & & & & \\
\hline$H 4$ & 0.180 & 0.098 & 0.259 & 0.309 & 0.400 & 0.059 & 0.240 & 0.058 & 0.460 & 0.431 & 0.520 & 0.380 & & & & \\
\hline H5 & & & & 0.018 & & & & & & 0.020 & & & & & & \\
\hline H6 & & 0.118 & 0.148 & 0.073 & 0.100 & 0.451 & 0.220 & 0.365 & 0.260 & 0.039 & 0.280 & 0.220 & & & & \\
\hline$H 7$ & & & & & & & & & & 0.235 & & & & & & \\
\hline$H 8$ & 0.040 & & & & & 0.020 & & & 0.040 & 0.039 & & & & & & \\
\hline H9 & & 0.020 & & & & & & & & & 0.100 & & & & & \\
\hline$H 10$ & & & & & & & & & 0.060 & & 0.020 & & & & & \\
\hline$H 11$ & & & 0.037 & & & & & & & & & & & & & \\
\hline$H 12$ & & & 0.019 & & & & & & & & & & & & & \\
\hline$H 13$ & & & & & & 0.059 & 0.120 & 0.173 & & & & 0.160 & & & & \\
\hline$H 14$ & & & & & & & & & & & & 0.020 & & & & \\
\hline$H 15$ & & & & & & & 0.120 & & & & & & & & & \\
\hline$H 16$ & & & & & & & & 0.038 & & & & & & & & \\
\hline$H 17$ & & & & & & & & & & & & & 0.620 & 0.300 & 0.660 & 0.438 \\
\hline$H 18$ & & & & & & & & & & & & & 0.120 & & 0.140 & 0.229 \\
\hline$H 19$ & & & & & & & & & & & & & 0.240 & 0.660 & 0.200 & 0.250 \\
\hline $\mathrm{H} 2 \mathrm{O}$ & & & & & & & & & & & & & 0.020 & & & \\
\hline$H 21$ & & & & & & & & & & & & & & & & 0.063 \\
\hline$H 22$ & & & & & & & & & & & & & & 0.020 & & \\
\hline$H 23$ & & & & & & & & & & & & & & 0.020 & & \\
\hline$H 24$ & & & & & & & & & & & & & & & & 0.021 \\
\hline
\end{tabular}

1, Brisbane; 2, Grafton; 3, Maryborough; 4, Toowoomba; 5, Cessnock; 6, Dubbo; 7, Goulburn; 8, Orange; 9, Horsham; 10, Ouyen; 11, Phillip Island; 12, Seymour; 13, Albany; 14, Busselton; 15, Mandurah; 16, Perth.

$(N)$, sample size, $\mathrm{H}$, haplotype.

A blank cell indicates the absence of a haplotype.

(C) The Genetical Society of Great Britain, Heredity, 85, 167-176. 
Table 4 Matrix of pairwise percentage sequence divergence estimates (below diagonal) and absolute distance (above diagonal) for populations of Australian magpies (Gymnorhina tibicen)

\begin{tabular}{|c|c|c|c|c|c|c|c|c|c|c|c|c|c|c|c|c|c|c|c|c|c|c|c|c|}
\hline$H$ & 1 & 2 & 3 & 4 & 5 & 6 & 7 & 8 & 9 & 10 & 11 & 12 & 13 & 14 & 15 & 16 & 17 & 18 & 19 & 20 & 21 & 22 & 23 & 24 \\
\hline 1 & & 4 & 6 & 3 & 4 & 4 & 3 & 5 & 5 & 1 & ( & 5 & 4 & 2 & 6 & & & 10 & 10 & 10 & 10 & 1 & & \\
\hline 2 & 68 & - & 2 & 1 & 2 & 2 & 1 & & 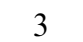 & & & & & & & & & & & & & & & \\
\hline 3 & & 0.34 & - & 3 & 2 & 4 & 3 & 5 & 5 & 5 & & 1 & & & & & 11 & & 10 & 2 & & & 10 & \\
\hline 4 & & & 0.51 & - & 1 & 1 & 2 & 2 & 2 & 2 & & 2 & 3 & & & & & & 9 & & & & & \\
\hline 5 & 0.6 & 0.3 & 0.34 & 0.17 & - & 2 & 3 & 5 & 3 & 3 & & 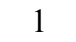 & 4 & & 4 & & S & 10 & 10 & 10 & 10 & & & \\
\hline 6 & & & 0.6 & 0. & 0.34 & - & 3 & 5 & & 3 & & & 4 & & & & 7 & & & & & & & 9 \\
\hline 7 & & & & & & 0.51 & - & 4 & 4 & 2 & & & & & & & 10 & & & 11 & & & & 12 \\
\hline 8 & & 0. & & & & & 0.68 & - & 6 & 4 & & & 1 & & & & & & & & & & & \\
\hline 9 & & & & & & & & 1.02 & - & 4 & & & 5 & & & & & & & & & & & \\
\hline 0 & & & & & & & & & 0.68 & & 5 & 4 & 3 & & 5 & 2 & 8 & & , & & & & & 0 \\
\hline & & & & & & & & & & & - & 1 & 4 & 2 & 6 & & 11 & 12 & 10 & 12 & 12 & & 10 & 3 \\
\hline & & & & & & & & & & & & - & 3 & & & & 10 & & $\mathrm{c}$ & 11 & & & & 2 \\
\hline & & & 0.68 & & & & & & & & & 0.5 & - & & & & & & & & & & & \\
\hline 14 & & & 0. & & & & & & & & & & 0.34 & & 4 & & & & & & & & & 9 \\
\hline 13 & & & 1. & 0. & & & & & & & & & & 0.68 & - & 3 & 7 & & & & & & & 9 \\
\hline & & & & & & & & & & & & & & & & & 6 & & & & & & & \\
\hline & & & & & & & & & & & & & & & & & - & & & & & & & \\
\hline & & & & & & & & & & & & & & & & & 0.17 & - & & & & & & \\
\hline & & & 1. & & & & & & & & & & & & & & 0.17 & & - & 3 & & & & \\
\hline & 1.6 & & 2.03 & 1.5 & & & & & & & & & & & & & & & 0.51 & - & 3 & 4 & 3 & 2 \\
\hline & & & 2.0 & & & & & & & & & & & & & & & & & 0.51 & - & & & \\
\hline & & & 2. & 1. & & & & & & & & & & & & & & & & & & - & 3 & \\
\hline & & & & & & & & & & & & & & & & & & & & & & & - & 3 \\
\hline & . & 1.86 & 2.20 & 1.69 & 1.86 & & 2.03 & 1.36 & 1.69 & 1.69 & 2.20 & 2.03 & 1.53 & 1 & 1 & & & & & & & & & \\
\hline
\end{tabular}

$\mathrm{H}$, haplotype.

further genetic analysis of magpie populations within currently sampled regions, in order to corroborate our results.

It is possible that observed differences in genetic structure between south-western and eastern regions may have resulted from historical evolutionary processes rather than differential levels of ongoing gene flow. This issue is being addressed in detail in a parallel study. Briefly, however, there are several reasons why we believe that this is unlikely to be the case:

1 mitochondrial gene trees revealed no significant subdivisions within eastern or within south-western regions;

2 there was no evidence of recent population expansion, because regional mitochondrial haplotype frequency distributions were significantly different from those predicted under Rogers's (1995) 'sudden expansion' model;

3 in eastern Australia there was a clear mitochondrial signature of isolation by distance suggesting that these populations are at equilibrium between gene flow and genetic drift and have existed in their present range for a long time.

Spatial structuring of genotypes will occur if offspring are reasonably philopatric to the natal site, either by active choice or passively because of limited dispersal tendencies (Avise, 1994). Thus, genetic differentiation is more likely to develop among magpie populations where juveniles tend towards philopatry (because these populations are more strongly influenced by genetic drift) than among populations characterized by higher levels of juvenile dispersal. In the present study therefore lower gene flow and larger group size in the south-west suggest higher levels of philopatry, compared to eastern regions where smaller groups probably result from more frequent juvenile dispersal leading to more extensive gene flow.

There was no clear pattern of genetic structuring and no significant difference in mean group size among eastern regions. This result is explained if juvenile dispersal after a breeding effort is the norm in most populations of eastern magpies.

\section{Conclusions}

Our results suggest that contrasting genetic structures have developed in G. tibicen as a result of differences in social system. Dispersal strategy for any particular magpie population may be determined by habitat quality. In poor habitats, extra pressure on resources 
imposed by retention of juveniles may favour a strategy whereby parents drive juveniles out of the territory each year before the next breeding effort. In the south-west, parents may tolerate the presence of young past year one, if important resources are in greater abundance. However, if resource competition can explain regional differences in magpie dispersal behaviour, exactly which resources 'drive' the system remains unclear. Conceivably, a suite of environmental variables (e.g. the amount of cleared land, number of nesting trees, relative prey abundance) determines the number of magpies a territory can support.

The significant differences in group size among magpie populations within the south-eastern region suggest that a more sensitive analysis of the spatial structure of alleles will be required to understand fully how dispersal is related to group size in this species. This may best be achieved by correlating gene frequencies within a territorial group with frequencies in neighbouring groups, and then determining if genetic relatedness decreases with distance to the greatest degree in the region with largest mean group size. Given the low levels of allozyme variability and the high incidence of mitochondrial haplotype sharing found in the present study, microsatellite loci may be most informative for this purpose because individual-based genetic descriptors are preferable for spatial autocorrelation analyses. These data may be used to indirectly estimate rates of interpopulation dispersal (e.g. Paetkau et al., 1995) and detect sex-biases in dispersal (e.g. Favre et al., 1997; Mossman \& Waser, 1999) through 'assignment indexing'. Finally, detailed demographic data for each territorial group will help determine if the number and survivorship of fledglings also influence group size in this species.

\section{Acknowledgements}

Funding for this research was provided by a Queensland University of Technology Postgraduate Research Grant and an Ethel Mary Read Scholarship awarded to A.M.B. Trapping permits were provided by the Queensland Parks and Wildlife Service, New South Wales National Parks and Wildlife Service, Parks Victoria and the Department of Conservation and Land Management, Western Australia.

\section{References}

AVISE, J. C. 1994. Mitochondrial DNA polymorphism and a connection between genetics and demography of relevance to conservation. Conserv. Biol., 9, 686-690.

BARRowClOUGH, G. F., CORBIN, K. W. AND ZINK, R. M. 1981. Genetic differentiation in the Procellarriiformes. Comp. Biochem. Physiol., 69, 629-632.
BARTON, N. H. 1992. The genetic consequences of dispersal. In: Stenseth, N. C. and Lidicker, W. Z. (eds) Animal Dispersal: Small Mammals as a Model, pp. 37-55. Chapman \& Hall, Melbourne.

BIRKY, C. W., JR, MARUYAMA, T. AND FUERST, P. 1983. An approach to population and evolutionary genetic theory for genes in mitochondria and chloroplasts, and some results. Genetics, 103, 513-527.

CARrICK, R. 1972. Population ecology of the Australian blackbacked magpie, royal penguin and silver gull. U. S. Dept. Interior Res. Report, 2, 41-99.

COOKE, F., PARKIN, D. T. AND ROCKWELL, R. F. 1988. Evidence of former allopatry of the two colour phases of lesser snow geese (chen caeru/escens caeru/escens). Auk, 105, 467-479.

Dobson, F. S., SMITH, A. T. AND GAO, W. X. 1998. Social and ecological influences on dispersal and philopatry in the plateau pika (Ochotona curzoniae). Behav. Ecol., 9, 622-635.

EXCOFFIER, L., SMOUSE, P. E. AND QUATTRO, J. 1992. Analysis of molecular variance inferred from metric distances among DNA haplotypes: application to human mitochondrial DNA restriction data. Genetics, 131, 479491.

FAVRe, F., BALlouX, F., GOUdET, J. AND PERrin, N. 1997. Female-biased dispersal in the monogamous mammal Crocidura russula: evidence from field data and microsatellite patterns. Proc. R. Soc. B, 264, 127-132.

FLEISCHER, R. C., LOWTHER, P. E. AND JOHNSTON, R. F. 1984. Natal dispersal in house sparrows: possible causes and consequences. J. Field Ornithol., 55, 444-456.

FRIESEN, V. L., PIATT, J. F. AND BAKER, A. J. 1996. Evidence from Cytochrome B sequences and allozymes for a new species of Alcid-the long-billed murrelet (Brachyramphus perdix). Condor, 98, 681-690.

GADGIL, M. 1971. Dispersal: population consequences and evolution. Ecology, 52, 253-261.

GREENWOOD, P. J. 1987. Inbreeding, philopatry and optimal outbreeding in birds. In: Cooke, F. and Buckley, P. A. (eds) Avian Genetics: a Population and Ecological Approach, pp. 207-222. Academic Press, London.

GREENWOOD, P. J., HARVEY, P. H. AND PERRINS, C. M. 1979. The role of dispersal in the great tit (Parus major): the causes, consequences and heritability of natal dispersal. J. Anim. Ecol., 48, 123-142.

HUDSON, R. R., SLATKIN, M. AND MADDISON, W. P. 1992. Estimation of levels of gene flow from DNA sequence data. Genetics, 132, 583-589.

HUGHES, J. M. AND MATHER, P. B. 1991. Variation in the size of territorial groups in the Australian magpie, Gymnorhina tibicen. Proc. R. Soc. Queensland, 101, 13-19.

HUGHeS, J. M., HESP, J. D. E., KALliOINEN, R., KEMPSTER, M., LANGE, C. L., HEDSTROM, K. E. ET AL. 1996. Differences in social behaviour between populations of the Australian magpie Gymnorhina tibicen. Emu, 96, 1-4.

KOENIG, W. D. AND PITELKA, F. A. 1979. Relatedness and inbreeding avoidance: counterploys in the communally nesting acorn woodpecker. Science, 206, 1103-1105.

MOSSMAN, C. A. AND WASER, P. M. 1999. Genetic detection of sex-biased dispersal. Mol. Ecol., 8, 1063-1067. 
MYERS, J. H. 1974. Genetic and social structure of feral house mouse populations on Grizzly Island, California. Ecology, 55, 747-759.

PAETKAU, D., CALVERT, W., STIRLING, I. AND STROBECK, C. 1995. Microsatellite analysis of population structure in Canadian polar bears. Mol. Ecol., 4, 347-354.

RICHARDSON, B. J., BAVERSTOCK, P. R. AND ADAMS, M. 1986. Allozyme Electrophoresis. Academic Press, Australia.

ROBINSON, A. 1956. The annual reproductory cycle of the magpie, Gymnorhina dorsalis Campbell, in south-western Australia. Emu, 56, 232-336.

ROGERS, A. R. 1995. Genetic evidence for a Pleistocene population explosion. Evolution, 49(4), 608-615.

SCHMIDT, L. G. 1987. Reproduction in the Western Form of the Australian Magpie (Gymnorhina Tibicen Latham, 1801): the
Interaction of Behavioural, Ecological and Hormonal Factors. MSc Thesis, University of Western Australia.

SLATKIN, M. 1987. Gene flow and the geographic structure of natural populations. Science, 236, 787-792.

SLATKIN, M. AND MADDISON, W. P. 1989. A cladistic measure of gene flow inferred from the phylogenies of alleles. Genetics, 123, 603-613.

SOKAL, R. R. AND ROHLF, F. J. 1995. Biometry. 3rd edn. W. H. Freeman, New York.

STENSETH, N. C. AND LIDICKER, W. Z., JR. 1992. The study of dispersal: a conceptual guide. In: Stenseth, N. C. and Lidicker, W. Z., JR (eds) Animal Dispersal: Small Mammals as a Model, pp. 5-20. Chapman \& Hall, London.

Wright, s. 1951. The genetical structure of populations. Ann. Eugenics, 15, 323-354. 